\title{
O TROLEBUS PASSA... A SOCIEDADE DORME NO PONTO
}

\author{
* Sinclair Mallot-Guy Guerra \\ * Ana J. Bertaseso

AMBIENTAL

Vantagens e desvantagens do trolebus, ressaltando seus aspectos ambientais positivos.

Advantages and desadvantages of trolley bus, highlighting its positive environmental aspects.

PALAVRAS-GHAVE:

Transporte, moio ambiente, eletricidade, trolebus.

\section{KEY WORDS:}

Transport, environment, electriclty, trolley bus.

\footnotetext{
- Professer Convidado Doutor, com Doutoramento em Economia da Energia pela Universidado de Paris.

* Mosirandos em Planejamento Estratégico na UNICAMP.
}

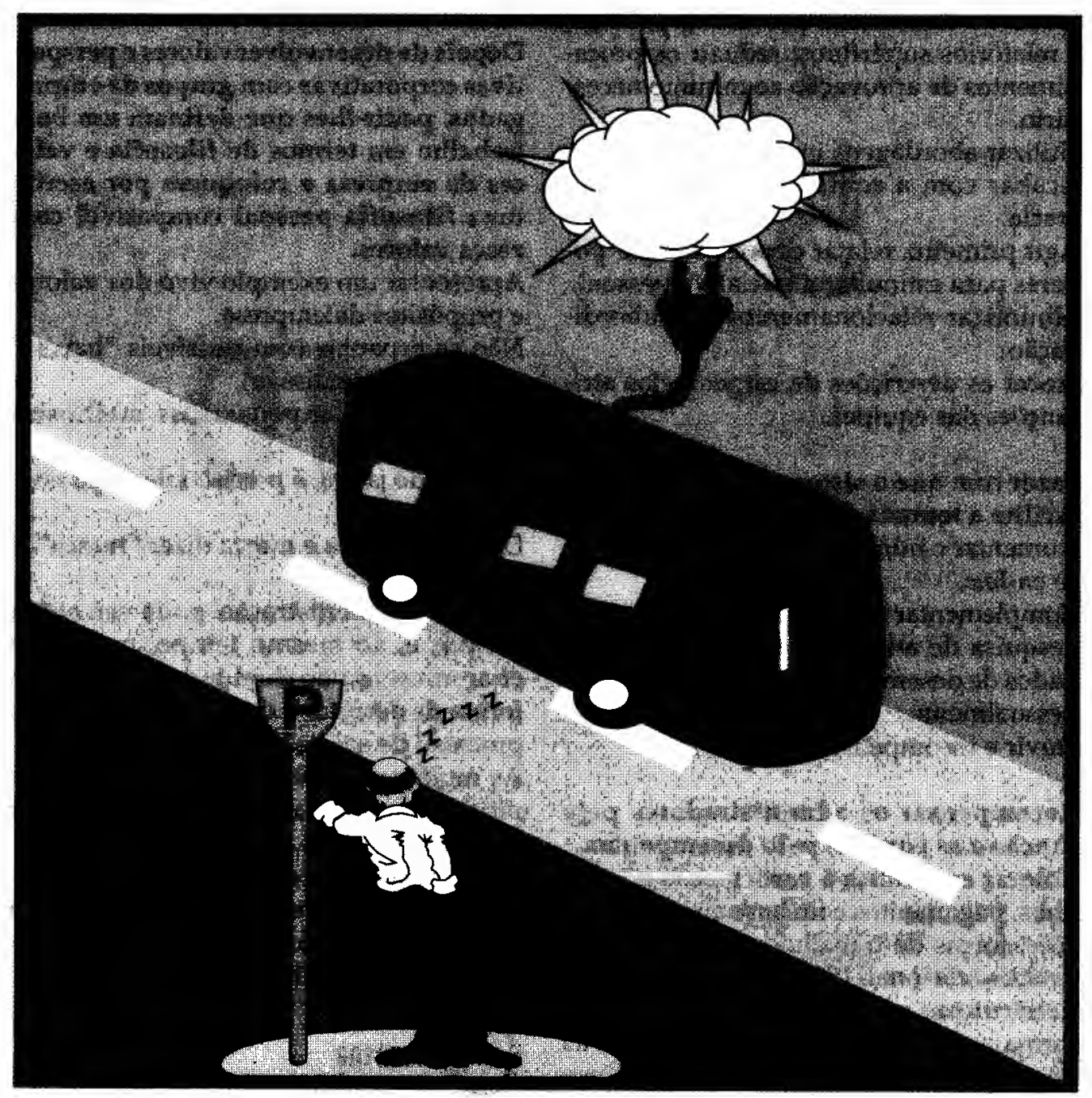


Partindo do pressuposto de que o suprimento energético de um país deve privilegiar os interesses globais da sociedade e que, para tanto, deve submeter-se a um planejamento racional das fontes e dos usos finais de energia, cabe ao Estado o papel de agente de fomento e de controle das açōes necessárias ao desenvolvimento sustentado da nação: equilibrando crescimento econômico, qualidade de vida e pujança da iniciativa privada.

No caso específico da implantação do sistema de trolebus, alternativa para transporte público com alto rendimento energético e de baixo impacto no ecossistema, a ausência de um consistente programa governamental de apoio deixou a experiência à mercê da competição com as facilidades existentes nos já convencionais ônibus movidos a óleo diesel. Isto ocorre em virtude de o sistema de ônibus a diesel possuir, em grande escala, tarifas subsidiadas e abrangente rede de fornecedores e, conseqüentemente, custos unitários significativamente inferiores, considerado apenas sob o aspecto empresarial.

Os custos indiretos, relacionados com a emissão de poluentes, importação de energéticos etc., acabam por não entrar na decisão das empresas operadoras (sejam elas públicas ou privadas), sendo rateados entre os contribuintes de todo o país.

Este trabalho analisa o papel do Estado como vetor indispensável à efetivação do uso de tecnologias energéticas alternativas, tomando como referência o caso da rede de trolebus recentemente desativada na cidade de Rio Claro (SP).

\section{TRANSPORTE E SOCIEDADE}

Grande parte do consumo energético nacional ocorre no meio urbano, onde a população e a renda estão concentradas, fator que influencia esse consumo diretamente. A população brasileira urbana cresceu de 18,7 milhōes de habitantes em 1950 para 147 milhões em 1989. Em 1940 a proporção da população total urbanizada era de $16 \%$. Chegou a $56 \%$ em $1970,63 \%$ em $1975,68 \%$ em 1980 e $76 \%$ em $1985^{1}$. No Estado de São Paulo o grau de urbanização era, em 1991, de $92,8 \%$ e, na região metropolitana, de $97,8 \%$.

A acelerada urbanização no Brasil transformou a demanda por serviços básicos como energia, habitação, saneamento, saúde, educação, segurança e notadamente transportes (principalmente nos grandes centros) em um imenso desafio para o planejamento energético.

A deficiência no planejamento do setor de transportes urbanos facilitou o surgimento dos seguintes problemas:

- inadequação da estrutura quanto à qualidade dos serviços, à racionalização do consumo energético e ao balanceamento entre os diferentes modos;

- inexistência de uma adequada política tarifária;

- saturação dos corredores de transporte;

- falta de integração entre estrutura de transporte e política de desenvolvimento urbano;

- carência de política e programa de investimento em transporte urbano;

- indefinição da questão financeira do setor; - escassez de recursos para melhoria dos transportes coletivos.

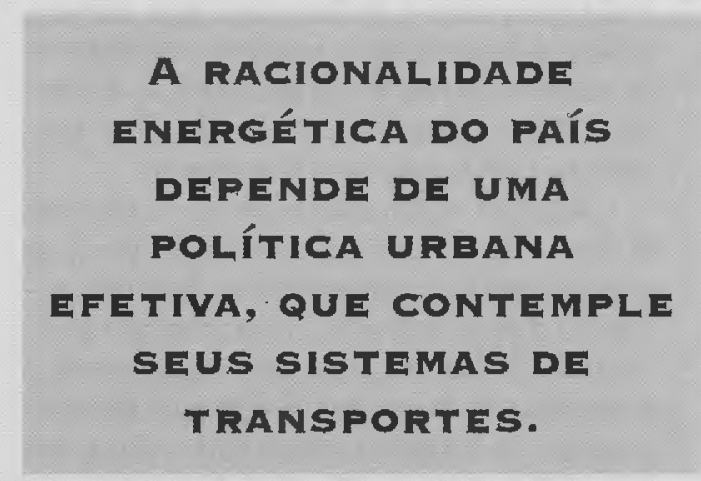

O crescimento desordenado do transporte de passageiros com veículos particulares onera a manutenção e os investimentos em infra-estrutura viária, contribuindo para o congestionamento das vias urbanas e para o excessivo consumo de combustível.

Nas nove principais regiões metropolitanas do país estima-se que foram realizadas, em 1986, cerca de 58 milhões de viagens/dia, somente por meios motorizados. Desse total, os transportes públicos respondem por $70 \%$, cabendo ao automóvel os $30 \%$ restantes.

Juntamente com o ônibus, principal veículo urbano de passageiros, integram o sistema de transporte coletivo os metrôs e trens metropolitanos, os táxis e, em algumas cidades, os trolebus e transportes aquaviários.
1. IBGE - Instituto Brasileiro de Geografia e Estatística. Relatório gerencial: populaçāo. Rio de Janeiro: IBGE, 1985.

2. COUCEIRO, J. H. et al. Reflexöes sobre o transporte urbano. Sảo Paulo: FUNDAP, 1991 (Documentos de Trabalho - DT/ QS2). 
3. MINISTÉRIO de Minas e Energia. Evolução do consumo fiscal por setor. Balanço energético nacional 1992, p. 14 (tabela 1.5).

4. Participação no consumo do setor transporte. Balanço energético... Op. cit., p. 45 (tabela 3.6)

Balanço energético consolidado. Balanço energético... Op. cit., p. 140 (anexo F.20).

Evolução da dependência externa de petróleo. Balanço energético... Op. cit. p. 58 (tabela 4.2)

7. PINTO Jr., H. Q. Comércioexterno de petróleo e derivados: estratégia pós-choque. Anais do I Congresso Brasileiro de Planejamento Energético. Campinas: UNICAMP, v. 3, p. 37, 1989

8. MINISTÉRIO de Minas e Energia. Gastos em divisas com importação do petróleo. Balanço energético... 0p. cit. p. 80 (tabela 7.12 )

9. LA ROVERE, E. L., BARREIROS, S. R. Conservação de energia em transportes. Anais do 1 Congresso Brasileiro de Planejamento Energético. Campinas: UNICAMP, v. 2, p. 345, 1989.

10. BUONFIGLIO, A. Questōes estratégicas dos derivados de petróleo. Anais do I Congresso. 0 p. cit., v. 3, p. 67 .

\section{OS ÔNIBUS RESPONDEM POR APROXIMADAMENTE $64 \%$ DAS VIAGENS REALIZADAS NAS REGIÓES METROPOLITANAS}

Os ônibus respondem por aproximadamente $64 \%$ das viagens realizadas nas regiōes metropolitanas, correspondendo a cerca de $90 \%$ das viagens de transporte coletivo. Os sistemas sobre trilhos, embora apresentem tendência a elevar sua participação relativa, não têm conseguido ultrapassar 6\%.

Nas cidades mais populosas, como Rio de Janeiro e São Paulo, nas quais os modos ferroviário e metroviário têm aumentado sua participação relativa no transporte coletivo, verifica-se a diminuição da modalidade ônibus e a elevação dos percentuais de transporte individual.

Caso não sejam adotadas medidas para alterar essa tendência, a situação pode se tornar caótica, sobretudo se houver aumento da participação do transporte individual. Aumento esse que acarretaria a necessidade de novos e vultosos investimentos na infra-estrutura rodoviária, em especial nas áreas urbanas. As vias de circulação vêm-se apropriando do espaço urbano, estimando-se que nas grandes cidades a área necessária para circular e estacionar veículos gira em torno de $50 \%$ do total.

\section{TRANSPORTE E ENERGIA}

Atualmente o consumo energético no Brasil gira em torno de 174 milhões $t E P$, dos quais 67 milhões $(38,7 \%)$ destinam-se ao setor industrial, 28 milhões $(16,4 \%$ ), ao setor residencial e 34 milhões $(19,7 \%)$ ao setor de transporte ${ }^{3}$.

No setor de transporte, $50 \%$ da energia consumida referem-se ao óleo diesel, $23,1 \%$ à gasolina automotiva e $17,2 \%$ ao álcool etílico .

Apesar de a eletricidade ser responsável por $46,3 \%$ da oferta total de energia secundária no Brasil, apenas $1 \%$ da ener- gia consumida em transporte é de origem elétrica ${ }^{5}$.

\section{TRANSPORTE E DEPENDÊNCIA EXTERNA}

Após o primeiro choque do petróleo (1973), a dependência externa do Brasil em relação a esse energético reduziu de $77,8 \%$ (1974) para 43,7\% (1991)

A redução da dependência energética foi conseqüência de programas de investimentos da Petrobrás, facilitando o aumento da produção nacional de petróleo, modificação da estrutura de refino e substituição de energético?

A queda da participação do petróleo no setor de transportes deve-se à entrada de um novo energético, o álcool, em substituição à gasolina. No mesmo período ocorreu o aumento do consumo do diesel, tornando-o um derivado de petróleo com importância crescente e estratégica.

Entretanto, a importação líquida de petróleo bruto e derivados encontra-se na ordem de US\$ 3,8 bilhões/ano, representando $19,7 \%$ das importações do país e $11,5 \%$ das exportações. A partir de 1985, $\mathrm{o}$ crescimento das importações totais tem sido maior que o de petróleo ${ }^{8}$.

Conforme demonstra La Rovere, o setor brasileiro de transporte permanece dependente do petróleo externo, apesar da redução dos preços internacionais, principalmente por estar baseado em modalidade rodoviária, ficando sujeito a novos aumentos de preços e ao esgotamento das reservas nacionais.

Projeções de especialistas ${ }^{10}$ indicam que os preços relativos do óleo diesel tendem a continuar aumentando em virtude dos elevados níveis de consumo. Dois fatores contribuiriam para isso: o melhor rendimento termodinâmico em relação à gasolina; a redução de poluentes, decorrente das exigências quanto à qualidade da gasolina.

Diante desse cenário e das dificuldades econômicas atuais no Brasil, o setor de transporte tem como alternativa de curto e médio prazos implementar um rigoroso programa de conservação de energia, optando pelo emprego de tecnologias que utilizem maior consumo de fontes energéticas renováveis. Para isso será necessária a participação do Estado enquanto agente de fomento e coordenação do planejamento. 
TRANSPORTE URBANO E INTENSIDADE ENERGÉTICA

Tomando por base a análise energética dos modos de transporte urbano realizada pelo Instituto de Pesquisas Tecnológicas (IPT) em $1981^{11}$, podemos comparar as diferentes intensidades energéticas verificadas no Brasil.

Entende-se por Intensidade Energética (I.E.) a quantidade de insumo energético por unidade de bem ou serviço realizado. Uma das maneiras de definir o produto do setor de transporte é o passageiro-quilômetro. Nesse caso utilizam-se estes conceitos: MJ/ passageiro.km.; MJ/veículo.km. e $\mathrm{MJ} /$ lugar.km.

No setor de transporte, o cálculo da I.E. normalmente só considera a energia direta, composta pela energia consumida na operação do sistema (muitas vezes só a energia de tração).

A energia aplicada em refino e distribuição de combustíveis, manufatura, manutenção de veículos e equipamentos, construção e manutenção de infra-estrutura (vias, estradas, estações etc.) é considerada energia indireta, não compondo o estudo de I.E.

O conteúdo energético dos combustiveis foi considerado igual aos valores utilizados internacionalmente ( $35 \mathrm{MJ} /$ litro de gasolina e $38 \mathrm{MJ} /$ litro de diesel).

A I.E. do transporte urbano de passa-

\section{QUADRO 1}

\section{INTENSIDADE ENERGÉTICA}

MJ/passageiro $\mathrm{km}$.

$\begin{array}{lccc}\text { Automóvel } & 3,10 & 4,90 & 0,98 \\ \text { Ônibus } & 0,52 & 15,20 & 0,23 \\ \text { Trolebus } & 0,33 & 9,40 & 0,10 \\ \text { Metrô } & 0,48 & 26,30 & 0,19 \\ \text { Trem Subúrbio } & 0,22 & 17,16 & 0,08\end{array}$

Fonte: Instituto de Pesquisas Tecnológicas, Relatório no: 167/81.

geiros em operação no Brasil teve os resultados apresentados no quadro 1.

Apesar dos já treze anos de realização desse relatório, podem ser destacadas como conclusões:

- o transporte por ônibus (ou trolebus) é mais eficiente energeticamente que o automóvel, sempre que a taxa de utilização for superior a cinco passageiros. km./ veículos.km.;

- veículos elétricos são mais eficientes que aqueles a diesel;

- formas de desincentivo ao uso do automóvel particular e incentivo ao transporte coletivo levam à conservação de energia (estacionamentos de integração, faixas privativas, prioridades semafóricas, aumento de freqüência, melhoria de rotas etc.).

\section{VANTAGENS E DESVANTAGENS DO SISTEMA TROLEBUS EM RELAÇÃO AO DIESEL}

Conforme estudos realizados pelo Ministério dos Transportes*, podem ser resumidas:

- vantagens do trolebus:

- utiliza energia elétrica (fonte nacional, preços internos);

- não polui o meio ambiente (menor ruído e sem $\mathrm{NO} x \in \mathrm{CO}_{2}$ );

- possibilita maior número de passageiros por veículo;

- apresenta durabilidade superior, maior vida útil e menos defeitos;

- possui capacidade para rampas de maior inclinação;

- é mais fácil de ser dirigido;

- tem maior aceleração;

- demanda menor consumo de energia.

* SILVA, A. T. ef al. Relatório do grupo de trabalho interministerial. Brasília: Ministério dos Transportes, s.d. (Programa Especial de Apoio à Implantação de Trolebus, v. 12; Portaria 55/MT, de 28 jan. 1977.)
- desvantagens do trolebus:

- exige sistema externo para alimentação de energia elétrica;

- apresenta dificuldades de ultrapassagem;

- sujeito a desprendimento da lança;

- exige maior altura de vãos livres;

- nāo pode ser utilizado fora das linhas estabelecidas;

- é dependente de energia da rede de contato.
11. RODRIGUES, M. et al. Perfil de eficiência energética dos modos de transporte urbano de passageiros. Relatório instituto de Pesquisas Tecnológicas $n^{\circ} 16.167 / 81,1981$. 
12. KASSAB, P., PARIS, M.G. A evolução dos sistemas de trolebus no mundo. Anais do IV Encontro Técnico sobre Sistema Trolebus. São Paulo: CMTC, 1984, p. 106.
De maneira geral, para se reduzir a energia consumida em transportes é necessário o desenvolvimento de um programa coordenado de ações, tanto para diminuir a I.E. como para otimizar o percurso e o número de viagens.

A obtenção de melhores resultados pode ser conseguida com incentivos concretos, no sentido de que os fabricantes procurem eficiência energética dos veículos e de que ocorra planejamento da utilização do meio de transporte mais adequado a cada situação. Em qualquer caso, enfatize-se, o papel do Estado (Federal, Estadual e Municipal) como agente de coordenação e fomento é imprescindivel.

\section{ASPECTOS AMBIENTAIS DOS SISTEMAS DE TROLEBUS}

Os estudiosos das questões ambientais têm, eles próprios, até aqui, dificultado a possibilidade de solucionar muitos dos problemas enfrentados. Isto porque os proble-

\section{AS VANTAGENS DO SISTEMA DE TROLEBUS APONTAM PARA ASPECTOS \\ ALTAMENTE POSITIVOS NO COMBATE A PROBLEMAS AMBIENTAIS.}

mas tomam dimensões tais que soluções simples deixam de ser consideradas.

A maior dificuldade na busca de soluçôes para tais problemas reside na falta de visão a respeito da possibilidade de se encontrar a resultante final da contribuição de pequenas parcelas.

A análise das vantagens. e desvantagens dos sistemas de trolebus aponta para contribuições simples, mas eficazes no tocante a tais soluções.

As vantagens do sistema de trolebus apontam para aspectos altamente positivos no combate a problemas ambientais, uma vez que o principal combustivel concorrente - nesse caso, o óleo diesel - deixa de ser consumido. Isso significa redução nas emissões de elementos poluentes, como $\mathrm{CO}_{2}$, Nox e $\mathrm{SO}_{2}$.

Merece destaque, também, o nível de ruído desse sistema que é altamente inferior ao dos ônibus tradicionais.

Finalmente, o seu baixo consumo de energia pode ser apontado como um dos elementos que contribuem para a valorização do sistema, caso o aspecto ambiental seja uma das variáveis consideradas.

\section{SISTEMA DE TROLEBUS NO MUNDO}

Conforme estudo realizado por kas$\mathrm{sab}^{12}$, em 1984, existiam no mundo 715 sistemas de trolebus, situados em 53 países. O primeiro funcionou em 1882, em Stalensee (Berlim). O mais velho - e mais extenso - que ainda sobrevive é o de Shangai (desde 1915), sendo o principal modo de transporte da China Continental. Entre as conclusões da pesquisa, destacam-se:

- duração dos sistemas existentes é superior à dos que já se extinguiram;

- mais da metade dos sistemas que não existem mais permaneceu em operação de 15 a 29 anos;

- a metade dos sistemas que estão atualmente em operação tem se conservado em funcionamento entre 20 e 34 anos;

- os fatores determinantes da desativação das redes de trolebus não obedecem a fatores constantes;

- a sua utilização é maior nos países de economia centralizada. Os países socialistas não sofreram pressão da indústria automobilística, mesmo naqueles em que há fartura de petróleo (ex-URSS).

O trabalho conclui que, embora largamente utilizado em todo o mundo, o sistema de trolebus muitas vezes é desativado em função do imediatismo político dos administradores, junto com a pressão das grandes indústrias automobilísticas (transporte individual), "... pois não há agora, e provavelmente nunca houve no passado, nenhuma razāo econômica para o abandono do sistema trolebus em favor do ônibus a diesel".

\section{SISTEMA DE TROLEBUS NO BRASIL}

No Brasil, o trolebus apareceu como substituto do bonde elétrico. A primeira e maior utilização do trolebus no transporte urbano brasileiro foi em São Paulo. A primeira linha foi implantada em 1947. Na década de 60 , a expansão foi descontinuada em função de excessiva preocupação com investimentos iniciais elevados; pressões da indústria automobilística e petrolífera; falta de planejamento; abando- 
no de conservação e incapacidade financeira para recomposição do sistema ${ }^{13}$.

Além do sistema de São Paulo (CMTC), encontram-se em funcionamento os de Recife (CTU), Santos (CSTC), Ribeirão Preto (TRANSERP) e Araraquara (CTA). Estão desativados os sistemas de Porto Alegre, Rio de Janeiro, Niterói, Campos, Belo Horizonte, Salvador, Fortaleza e, recentemente, o de Rio Claro.

Em 1984 previa-se a instalação dos sistemas de Campinas, Cuiabá, Curitiba, Goiânia, Natal e Belém ${ }^{14}$, o que acabou não ocorrendo.

Em 1977 o Ministério dos Transportes deu início ao Programa Especial de Apoio à Implantação do Sistema de Ônibus Elétrico (trolebus). A seguir são tecidas algumas considerações extraídas do relatório do Grupo de Trabalho Interministerial criado especificamente para estudar o assunto ${ }^{15}$, revelando as precárias condições do sistema existente, carente de modernização e recuperação:

- a frota brasileira de trolebus era de 406 veículos, sendo que $20 \%$ encontravamse em reforma;

- a idade média da frota era de 15 anos, existindo muitas unidades com mais de 20 anos de serviço;

- havia diversidade de marcas, com grande dificuldade de reposição de peças.

Esses aspectos, ao contribuirem decisivamente para excessivos custos de operação e manutenção da frota, colaboraram para a desativação de sistemas.

\section{SISTEMA TROLEBUS DE RIO CLARO: ESTUDO DE CASO}

Na década de 80 , dentro da política de substituição de energéticos importados, a Companhia Energética de São Paulo (CESP) iniciou estudos no sentido de se analisarem as possibilidades de maior participação desse setor na eletrificação dos transportes coletivos urbanos.

Os investimentos em estações retificadoras e redes de contato, até então construídas e operadas pelo transportador, apresentavam-se como a maior dificuldade para a implantação desses sistemas de trolebus ou para a expansão dos existentes.

Sob essa ótica, a CESP e a Prefeitura Municipal de Rio Claro (PMRC) assinaram carta de intenções para a implantação de um projeto-piloto, inédito no país, segun-

\section{QUADRO 2}

\section{INDICADORES}

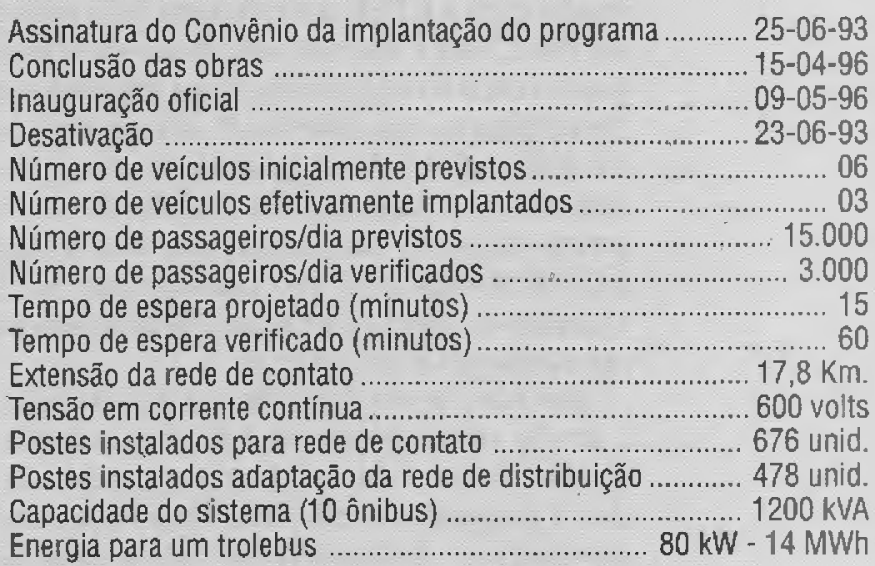

Fonte: CESP. Relatório básico, mai. 1992. (Projeto-piloto do trolebus em Rio Claro). Convênio CESP-PMRC, 25 jun. 1983, PROTRAN

Engenharia. Estudo de viabilidade de utilização do trolebus ODC/

Siemens. Rio Claro: PMRC/EMDERC, 1984.

\section{QUADRO 3}

\section{CUSTOS BÁSICOS (US\$ mil)}

Trolebus novo..................................................170

Trolebus reformado

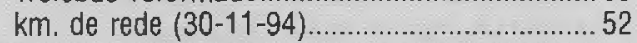

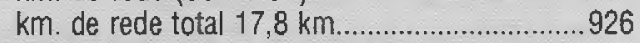

Custo do sistema elétrico (CESP) ...................1.238

Estação retificadora.............................................312

Fonte: CESP, PROTRAN. Op. cit.

do a qual a concessionária de energia assumiria todo o investimento do sistema de alimentação e a transportadora (Prefeitura) seria responsável pelos veículos.

Essa forma de atuação da concessionária, proposta pela CESP, foi consolidada através do Decreto n. 21.177 de 18-08-93 instituindo o Programa de Trolebus no Estado São Paulo.

A remuneração do investimento da CESP seria assim composta: energia faturada com tarifa específica para tração elétrica, com desconto de $45 \%$; parcelas mensais de aproximadamente US $\$ 1.000$ para cobrir custos de amortização e manutenção da rede de contato e estação retificadora.

Os quadros 2 e 3 apresentam os principais dados do projeto.

Assim, como citado, o sistema de trolebus de Rio Claro teve como ponto de
13. SILVA, A. T. Op. cit.

14. WAISMAN, J, RODRIGUEZ, P. S. M. S. Avaliaçāo preliminar do mercado brasileiro de trolebus. Anais do IV Encontro Técnico... Op. cit., p. 7.

15. SILVA, A. T. Op. cit. 
partida o interesse da CESP em ativar um programa-piloto de substituição de derivados de petróleo. A partir do acordo firmado com a CESP, a Prefeitura Municipal de Rio Claro elaborou um plano de transporte coletivo que sinalizava a viabilidade de utilização do trolebus ${ }^{16}$. Nesse estudo foi realizado extenso levantamento de dados relativos à demanda e à oferta de transporte coletivo na cidade de Rio Claro (80.000 dados e 15.000 passageiros/dia), visando a identificar suas características operacionais e de serviço.

Em função do diagnóstico da situação, e tendo como premissa básica a introdução do sistema de trolebus, foram estudadas e propostas melhorias visando à reorganizaçāo e racionalização do sistema de transporte coletivo.

Os dados mostraram a baixa qualidade dos serviços existentes, expressa pela reduzida freqüência e irregularidade, elevado tempo de espera e pouca qualidade de conforto, mesmo com o sistema apresentando rentabilidade satisfatória e índices operacionais razoáveis.

Entre as diversas ações implementadas estavam:

- introduzir o sistema de corredores;

- reestruturar as redes de linhas;

- redistribuir os pontos de parada $(500 \mathrm{~m})$;

- programar a oferta em função da demanda;

- implantar serviço de informações ao usuário.

O sistema de trolebus foi criado a partir do projeto que previa a recuperação de dez carros elétricos da Companhia Municipal de Transportes Coleti-

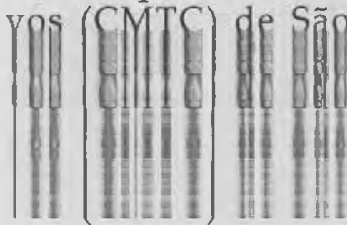

Paulo (carros da década de 50). Para tanto, a PMRC montou uma oficina de recuperação.

O sistema esteve funcionando com dois carros até 1988, quando era responsável por $10 \%$ do transporte coletivo da cidade, com fluxo aproximado de 3.000 pessoas / dia. Nessa época entrou em funcionamento a terceira unidade.

Em 31-12-88, a Prefeitura inaugurou a nova Estação Rodoviária Intermunicipal, que se encontra fora do traçado original do trolebus. Esse fator, aliado às dificuldades técnico-econômicas de recuperação dos veículos obsoletos comprados da CMTC e, ainda, à baixa produtividade operacional do sistema, fizeram com que fosse tomada a decisão de se substituir os trolebus por ônibus a diesel.

A desativação do sistema comprometeu a recuperação dos investimentos por parte da CESP, que vinha tentando manter o sistema em funcionamento por meio de sucessivos acordos de adiamento do pagamento das parcelas devidas pela Prefeitura. No momento, além da procura de entendimentos com a PMRC, a CESP tenciona estudar viabilidades alternativas ao investimento, já que a desativação pura da rede ou sua manutenção implica novos investimentos.

Do ponto de vista da Prefeitura, os principais motivos da desativação do sistema foram:

- baixa confiabilidade nos veículos (quebras freqüentes);

- altos custos operacionais (peças e estrutura);

- prejuízo global do sistema misto (trolebus + diesel);

- topografia plana, facilitadora do transporte individual por bicicletas;

- centralização do Distrito Industrial, fora do trajeto;

- isenção de tarifas para idosos (60 anos),

- ausência de recursos para investimento na frota.

Esses fatores sustentaram a decisão da Prefeitura de privatizar o sistema de transporte, através de concorrência pública, concomitantemente com a desativação das linhas de trolebus, para as quais, no entanto, segundo informaçōes da PMRC, todos os transportadores concor- rentes colocaram restrições. Com a privatização, o sistema radial foi também desativado, tendo em vista que só estaria funcionando por privilegiar a linha do trolebus.

Antes da privatização o sistema estava composto por cinco trolebus (responsável por aproximadamente $30 \%$ do número de passageiros transportados) e 23 onnibus a diesel. Hoje existem 25 veículos a diesel. 
Quanto ao número de passageiros no período de transição, observem-se os dados apresentados no quadro 4 .

Os números referentes ao transporte de passageiros pelo sistema de trolebus são uma prova cabal de que há viabilidade nessa opção. Segundo estudo desenvolvido em 1976 pela Empresa Municipal de Planejamento (EMPLASA) de São Paulo, o sistema de trolebus tem solução econômica nos transportes públicos, desde que estejam, no mínimo, dentro das faixas demonstradas no quadro 5.

\section{CONCLUSÕES}

O adensamento da população brasileira em grandes cidades; o crescimento exponencial da frota automobilística; a necessidade de racionalização do uso de energia e o emergente controle dos processos de poluiçấo ambiental, configuram um cenário no qual é imprescindível a participação do Estado no papel de agente de planejamento e de fomento de tecnologias mais eficientes.

Isto ocorre, notadamente, com relação ao consumo de energia e meios de transportes, já que significativa parcela do consumo energético nacional é de derivados de petróleo, representado principalmente pelo transporte em áreas urbanas.

A conjugação coordenada de todos esses fatores acaba não ocorrendo do ponto de vista microeconômico (iniciativa privada). É necessária a participação do Estado para que soluções encontradas sejam produtivas para a sociedade como um todo, do ponto de vista macroeconômico e, seguramente, de longo prazo.

A racionalidade energética do país depende de uma política urbana efetiva, que contemple seus sistemas de transportes. As áreas prioritárias de atuação são constituídas pelas regiões metropolitanas (capitais e cidades de porte médio), caracterizadas como pólos de desenvolvimento regional. Dentro dessas diretrizes, os programas prioritários atingem as seguintes áreas:

- trens de subúrbio;

- metrôs;

- trolebus;

- infra-estrutura viária;

- racionalização do transporte público;

- capacidade e segurança de tráfego;

- terminais;

- transporte hidroviário;

- educação e participação comunitária;
QUADRO 4

\section{PASSAGEIROS/MÊS/1993}

$\begin{array}{lccc}\text { Mês } & \begin{array}{c}\text { Onibus a } \\ \text { Diesel }\end{array} & \text { Trolebus } & \begin{array}{c}\text { \% Trolebus } \\ \text { Diesel }\end{array} \\ \text { Janeiro } & 242.583 & 108.277 & \text {. } \\ \text { Fevereiro } & 246.061 & 208.272 & 84,64 \\ \text { Março } & 283.689 & 125.847 & 44,36 \\ \text { Abril } & 271.704 & 119.549 & 43,99 \\ \text { Maio } & 291.638 & 124.204 & 42,59 \\ \text { Junho } & 372.766 & 107.174 & 28,75 \\ \text { Julho } & 390.000 & \text { desativadio } & - \\ \text { Agosto } & 394.000 & \text { desativado } & -\end{array}$

Fonte: Empresa Pública Municipal de Desenvolvimento de Rio Claro - EMDERC/PMRC.

\section{QUADRO 5}

$\begin{array}{lr}\text { TECNOLOGIA } & \text { FAIXAS PASSAGEIROS/HORA } \\ \text { Ônibus } & 0 \mathrm{a} 3.500 \\ \text { Ônibus } & 2.000 \mathrm{a} 8.000 \\ \text { Trolebus } & 2.000 \mathrm{a} 8.000 \\ \text { Trolebus articulado } & 4.000 \mathrm{a} 12.000 \\ \text { Pré-metrô } & 18.000 \mathrm{a} 35.000 \\ \text { Metrô } & 30.000 \mathrm{a} 70.000\end{array}$

Fonte: Empresa Municipal de Planejamento - EMPLASA. Estudo de Viabilidade dos Sistemas de Trolebus, 1976.

- estudos e pesquisas para transportes urbanos;

- capacitação de recursos humanos.

Esses estudos devem ser acompanhados da análise de outras implicações tais como poluịção, valorização do solo, oferta e demanda de empregos etc., visto que os volumes de investimentos necessários são grandes e o sistema não pode ser concebido isoladamente.

A experiência do sistema de trolebus de Rio Claro pode funcionar como exemplo concreto de que apenas o atendimento de viabilidades técrico-econômicas não são suficientes para garantir o sucesso de um empreendimento tão complexo, que envolve energia e transporte público. É necessário um compromisso social de longo prazo, capaz de sustentar o incentivo à realização dos serviços públicos essenciais, com tecnologias eficientes, do ponto de vista energético, e factíveis, do ponto de vista empresarial. $\square$

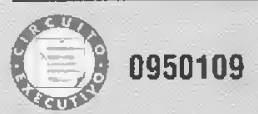

